body composition; a multiplicative interaction term for $\mathrm{AC}$ growth from 34 weeks to birth and 6 year prudent diet score was added. Confounding variables (determined by a Directed Acyclic Graph) were 9-year height, age at DXA, sex, breastfeeding duration, maternal BMI, education, smoking in pregnancy, late pregnancy vitamin $\mathrm{D}$ and pregnancy weight gain.

Results Greater AC growth z-scores from birth to 6 months, 2-3 years and 3-6 years were associated with higher fat mass and percentage fat at 9 years. The interaction between AC growth from 34 weeks to birth and 6 year prudent diet score was statistically significant for total fat $(p=0.006)$ and percentage fat $(p=0.005)$, but not for total lean or bone mass. Amongst children with low late gestation AC growth, lower prudent diet scores were associated with greater 9-year total and percentage fat, whereas amongst children with high AC growth in late gestation there was little effect of prudent diet score on total and percentage fat.

Conclusion Individuals showing late gestation faltering of fetal growth who then had an unhealthy imprudent childhood diet had greater adiposity, while childhood diet was less influential on adiposity in individuals whose fetal growth had not faltered, providing evidence in support of the mismatch hypothesis.

\section{OP40 \#ASSOCIATION BETWEEN SUPERMARKET CHECKOUT FOOD POLICIES AND PURCHASES OF COMMON LESS HEALTHY CHECKOUT FOODS: INTERRUPTED TIME SERIES ANALYSES AND META-ANALYSIS OF NATURAL EXPERIMENTS}

${ }^{1} \mathrm{KR}$ Ejlerskov, ${ }^{2} \mathrm{M}$ Stead, ${ }^{3} \mathrm{AJ}$ Adamson, ${ }^{1} \mathrm{M}$ White, ${ }^{1} \mathrm{~J}$ Adams ${ }^{*} .{ }^{1}$ Centre for Diet and Activity Research, MRC Epidemiology Unit, University of Cambridge, Cambridge, UK; ${ }^{2}$ Institute for Social Marketing, University of Stirling, Stirling, UK; ${ }^{3}$ Human Nutrition Research Centre and Institute for Health and Society, Newcastle University, Newcastle upon Tyne, UK

\subsection{6/jech-2018-SSMabstracts.40}

Background Supermarkets' in-store marketing influences food purchasing and consumption. This marketing includes positioning food at checkouts. Checkouts provide a unique location, through which all customers must pass and where some may linger. The majority of supermarket checkout food is less healthy.

Supermarket activities with potential to improve population health are increasing. One example is voluntary, supermarketled policies on checkout foods.

We studied the immediate and sustained impacts of the introduction of voluntary, supermarket-led checkout food policies on purchases of commonly displayed checkout foods.

Methods Eight national supermarket groups were included. Intervention groups were those that changed their checkout food policy between January 2014 and February 2016 ( $n=6)$.

Supermarket group-specific data on purchases of common checkout foods was obtained from Kantar Worldpanel's 'Take Home' panel: a representative panel of UK households $(n \approx 30,000)$ who record all food and beverage purchases brought into the home. We obtained data at the four-weekly level, multiplied up and weighted by Kantar to represent the total UK market. Kantar also provided supermarket group market share data.

Common checkout foods, selected based on a previous survey, were: single-unit packages of sugary confectionery $(\leq 225 \mathrm{~g})$, chocolate $(\leq 125 \mathrm{~g})$, and crisps $(\leq 50 \mathrm{~g})$.
Controlled interrupted time-series analyses were conducted of changes in purchases of common supermarket checkout foods in the 14 four-weekly periods before, and the 13 fourweekly periods after, implementation of checkout food policies - in units purchased per percentage market share. As different supermarket groups implemented policies at different times, separate analyses were conducted for each group. Supermarket groups that did not change their policies during the study period were used as comparators $(n=2)$. Results were synthesised using random-effects meta-analyses.

Data analyses were conducted in Stata/SE v14.2 and $R$ v3.3.1.

Results In meta-analyses, implementation of supermarket checkout food policies was associated with a statistically significant decrease in purchases of common checkout foods of 137160 units per percentage market share in the four weeks following policy implementation $(95 \%$ confidence intervals (CI): $-252,690$ to $-21,630)$. By 12 months this effect had diminished $(-57,080 ; 95 \% \mathrm{CI}-167,760$ to 53,590$)$.

Conclusion Implementation of supermarket checkout food policies was associated with an immediate reduction in purchases of sugary confectionery, chocolate and crisps that was not sustained at one year. Voluntary supermarket-led activities have the potential to decrease purchases of less healthy foods. Initial effects may be undermined over time by changes in behaviour of supermarkets, consumers, or both. The data are observational and exclude purchases not brought home.

\section{OP41 NUTRITIONAL CONTENT OF HOUSEHOLD FOOD PURCHASES: STUDY OF TRENDS AND SOCIO-ECONOMIC INEQUALITIES IN BRITAIN 2012-2017}

${ }^{1} \mathrm{~L}$ Cornelsen*, ${ }^{1} \mathrm{~N}$ Berger, ${ }^{2} \mathrm{R}$ Smith, 'S Cummins. 'Department of Public Health, Environments and Society, London School of Hygiene and Tropical Medicine, London, UK; ${ }^{2}$ Faculty of Public Health and Policy, London School of Hygiene and Tropical Medicine, London, UK

\subsection{6/jech-2018-SSMabstracts.41}

Background Tackling the rise of non-communicable diseases has become a significant challenge for public health across the globe. Understanding diets and dietary behaviours is important due to significant links between poor diet and obesity, diabetes, cardio-vascular diseases and many cancers. This study aims to describe the patterns of expenditures on food and beverages purchased for at-home consumption in Great Britain and to examine socio-economic inequalities in the nutritional content of purchases.

Methods We use home-scan (Kantar Worldpanel) data covering daily purchases of all foods and beverages for at-home consumption in the period $2012-17$ by $\sim 32,000$ British households. The sample is nationally representative with respect to age and sex of the main shopper in the household, geographical region and socio-economic status. We estimate daily per capita purchases of energy, all sugars and saturated fats from 26 healthier and less healthy food groups defined using a nutrient profile model (UK Department of Health). Results are further stratified by social grade (A/B, C1/C2 and D/E).

Results Preliminary results show that daily per capita purchases of energy and sugar decreased between 2012 and 2017 from $2099 \mathrm{kcal}$ (95\% CI 2,091 to $2106 \mathrm{kcal})$ to $2002 \mathrm{kcal}$ (95\% CI 1,995 to $2009 \mathrm{kcal})$ and $116 \mathrm{~g}$ (95\% CI 116 to $117 \mathrm{~g})$ to $108 \mathrm{~g}$ (95\% CI 108 to $109 \mathrm{~g})$ respectively. Expenditure on saturated fat remained constant at $31 \mathrm{~g}$ (95\% CI 31 